\title{
A Direct Electrochemical Biosensing Platform Constructed by Incorporating Carbon Nanotubes and Gold Nanoparticles onto Redox Poly(thionine) Film
}

\author{
Hui Feng, $*$,** Hua Wang, ${ }^{* \dagger}$ Yun Zhang,* Bani YAn,* Guoli Shen,* and Ruqin YU* \\ * State Key Laboratory of Chemo/Biosensing and Chemometrics, College of Chemistry and \\ Chemical Engineering, Hunan University, Changsha 410082, P. R. China \\ **Department of Chemistry and Chemical Engineering, Hunan Act and Science University, \\ Changde 415000, P. R. China
}

\begin{abstract}
A direct electrochemical biosensing platform has been fabricated by covalent incorporation of carbon nanotubes (CNT) and gold nanoparticles (GNP) onto the poly(thionine) (PTH) film deposited by electropolymerization. With the synergic effects of the composite nanomaterials together with the excellent mediating redox polymer, the proposed platform could allow for faster electron transfer and higher enzyme immobilization efficiency than the platforms designed by using CNT or GNP alone. Comparison studies indicated that the as-developed $\mathrm{H}_{2} \mathrm{O}_{2}$ sensor could show greatly improved performances of amperometric responses.
\end{abstract}

(Received June 7, 2006; Accepted August 28, 2006; Published February 10, 2007)

Recent decades witness increasing amounts of interest of developing enzyme-based electrochemical biosensors which combine the highly specific enzymatic reaction with the sensitive electroanalytical signal transduction. The preparation of these devices usually entails an electrical connection between the enzymatic redox centers and the electrodes, typically by introducing a redox mediator. ${ }^{1,2}$ It would be preferable to immobilize the electron-transfer mediators on the electrode surfaces so as to prepare direct or reagentless electrochemical sensors, mostly known as the third-generation enzyme biosensors. ${ }^{3,5}$ Successful mediated biosensors have been fabricated with enzymes either chemically modified with the electron relays ${ }^{6}$ or tethered to the mediating redox polymers premodified on the electrodes.,7-10 However, some redox mediators in use may still suffer from low electron transfer efficiency or the inherent drawback of part solubility in the bulk solution leading to a gradual leaking of mediators during continuous sample analysis.

In recent years, nanostructured materials with unique physical and chemical properties have been explored intensively for electrocatalytic sensing applications. ${ }^{11}$ Nanoparticles such as gold particles (GNP) are employed as a kind of potential nanomaterials that may allow for electron transfer between the anchored enzyme and the electrode, facilitating the direct electrochemical analysis.,11 GNP can also show a high affinity to a wide range of biomolecules and chemical ligands. ${ }^{12,16}$ Carbon nanotubes (CNT) represent another important group of nanomaterials for the development of ultrasensitive electrochemical biosensors, with special properties of promoting electronshuttling reactions with electroactive species (i.e., enzymes). ${ }^{17,18}$ However, the insolubility of CNT in most solvents including water may be encountered while fabricating a practical CNTbased enzyme electrode. ${ }^{19}$ Some efforts have been devoted to

$\dagger$ To whom correspondence should be addressed.

E-mail: huawang@hnu.cn the development of the CNT-based sensors by integration of CNT with other materials including polymers, redox mediators and metal nanoparticles. ${ }^{20,23}$ It is well established that either singlewall or multiwall CNT could strongly interact with the thionine molecule of the electron-shuttling mediator, with greatly improved solubility of original CNT. ${ }^{21}$ Moreover, some metal nanomaterials such as GNP may be firmly adsorbed on the films of thionine redox with amine groups.

In the present work, a novel direct electrochemical biosensing platform has been proposed by incorporation of CNT and GNP onto the glass carbon (GC) electrodes modified with poly(thionine) (PTH) by electropolymerization. Horseradish peroxidase (HRP) as a test model of enzyme was immobilized on the resulting PTH-CNT-GNP platform. The performances of the developed $\mathrm{H}_{2} \mathrm{O}_{2}$ sensors were studied and comparied with those fabricated by other platforms separately using CNT or GNP alone, and the common cross-linking reagent.

\section{Experimental}

\section{Reagents and instruments}

Carbodiimide hydrochloride (EDC), $N$-hydroxysuccinimide (NHS) and horseradish peroxidase (HRP, RZ > 3.0, $250 \mathrm{U} / \mathrm{mg}$ ) were purchased from Sigma. Multiwall carbon nanotubes (CNT, $\sim 95 \%$ purity) were obtained from Shenzhen Nanotech Port Co., Ltd. (Shenzhen, China). Gold nanoparticles (GNP, with average diameter of $10 \mathrm{~nm}$ ) synthesized by reduction of $\mathrm{HAuCl}_{4}$ solution with sodium citrate were purchased from SinoAmerica Biological Products (Beijing, China). Thionine and hydrogen peroxide $\left(\mathrm{H}_{2} \mathrm{O}_{2}, 30 \%\right)$ were obtained from Shanghai Chemical Reagent Company (Shanghai, China). Glutaraldehyde (GLU) was purchased from Wuhan Organic Chemicals (Wuhan, China). Phosphate buffer solution (PBS, $\mathrm{pH}$ 7.0) that was prepared using $\mathrm{KH}_{2} \mathrm{PO}_{4}$ and $\mathrm{Na}_{2} \mathrm{HPO}_{4}(0.067$ $\mathrm{M})$ was utilized as the supporting electrolyte. Other chemicals 


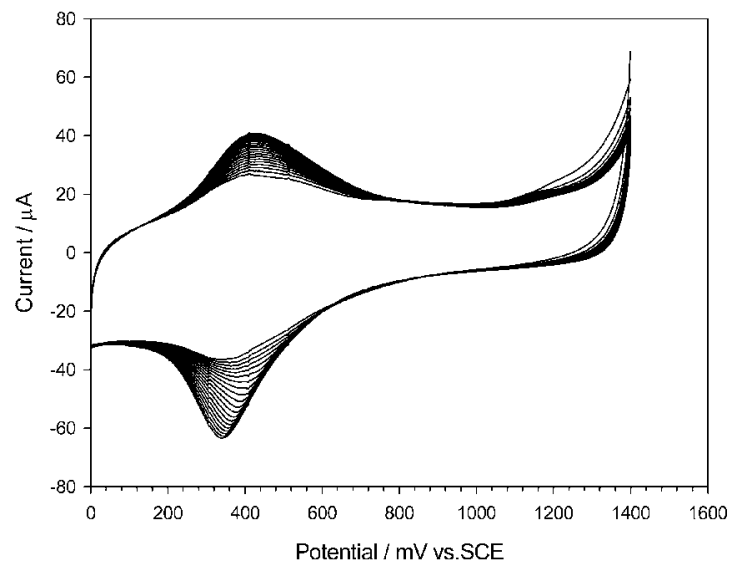

Fig. 1 In-situ electropolymerization of thionine onto the GC electrode with thionine monomer in acetonitrile solution by cyclically scanning from 0 to $1.4 \mathrm{~V}$ at a scan rate of $40 \mathrm{mV} / \mathrm{s}$.

were of analytical grade. Doubly distilled water was used throughout all experiments.

Cyclic voltammetric (CV) and amperometric measurements were performed on the $\mathrm{CHI} 760 \mathrm{~B}$ electrochemical workstation (Shanghai Chenhua Instrument Co., Ltd., China). A threeelectrode system was employed: it included one of the glass carbon (GC) electrodes with different sensing platforms as the working electrode, a saturated calomel electrode (SCE) as the reference electrode against which potentials were referred to SCE in all experiments, and a platinum foil electrode as the auxiliary electrode.

\section{In situ electropolymerization of PTH}

The GC electrode ( $2 \mathrm{~mm}$ diameter) was polished successively with finer sandpapers of $0.3 \mathrm{~mm}$ and $0.05 \mathrm{~mm}$ alumina slurry on microcloth pads (Shanghai Chenhua Instrument Co., Ltd., China) to attain a "mirror-like" surface. The electrode was then ultrasonically rinsed with doublely distilled water and with ethanol. Following such pretreatment, the electrode was immersed into $1.0 \mathrm{mM}$ thionine monomer in acetonitrile solution that was deaerated with $\mathrm{N}_{2}$ for 20 min. The in situ electropolymerization was then conducted by cyclically scanning from 0 to $1.4 \mathrm{~V}$ ( $v s$. SCE) at a scan rate of $40 \mathrm{mV} / \mathrm{s}$ for 40 cycles until a steady-state current-voltage curve was obtained (Fig. 1), thus yielding a PTH modified GC electrode.

\section{Construction of different sensing platforms}

The resulting PTH-modified electrodes were employed separately for preparing different sensing platforms. The first modified electrode was immersed in $2.5 \%$ GLU solution for $1 \mathrm{~h}$ and then washed with water to form the PTH-GLU platform. A portion of the CNT suspensions, which were chemically activated in the mixture solution of EDC and NHS as described elsewhere, ${ }^{23}$ was dropped onto the second modified electrode to be incubated overnight at $4^{\circ} \mathrm{C}$, thus forming the PTH-CNT platform. The direct addition of a portion of GNP suspension onto the third modified electrode to be reacted overnight at $4^{\circ} \mathrm{C}$ could produce the PTH-GNP platform. Accordingly, the incorporation of CNT and GNP onto the fourth modified electrode could obtain the PTH-CNT-GNP platform, where the electrode was soaked into a mixture of GNP and chemically activated CNT suspensions by $1: 1(\mathrm{v} / \mathrm{v})$ to be incubated overnight at $4^{\circ} \mathrm{C}$, and then washed twice with water.

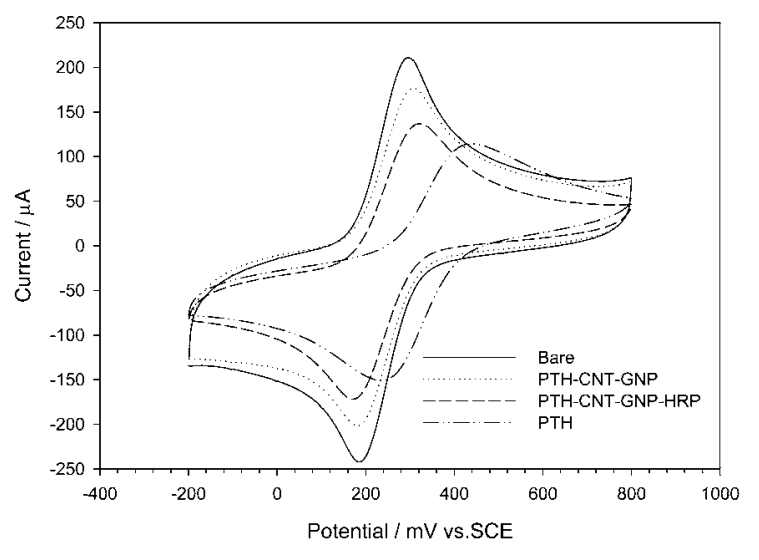

Fig. 2 The process CV characterization for the enzyme electrode prepared successively with PTH, CNT-GNP, and HRP by CV experiments with $10 \mathrm{mM} \mathrm{K}_{3} \mathrm{Fe}(\mathrm{CN})_{6}$ containing $0.1 \mathrm{M} \mathrm{KCl}$ at a scan rate of $40 \mathrm{mV} / \mathrm{s}$.

\section{Electrochemical measurement procedures}

The electrodes so prepared with four kinds of sensing platforms were separately utilized for preparing different enzyme sensors. The similar preparation process was performed for the sensors by incubating each of these electrodes with a portion of $15 \mathrm{mg} / \mathrm{mL}$ HRP solution overnight at $4^{\circ} \mathrm{C}$, followed by the successive washing with water and PBS $(\mathrm{pH}$ 7.0).

The CV experiments were carried out in the unstirred test solution in an electrochemical cell $(10 \mathrm{~mL})$, and amperometric measurements were performed in the solutions magnetically stirred at room temperature. All potentials in the present experiments were measured versus the SCE. Note that, each of these experiments was repeated at least three times, including the different electrode preparations.

\section{Results and Discussion}

Design of the enzyme electrode with the PTH-CNT-GNP platform

The electrode was modified with a mediating redox polymer of thionine by the electropolymerization, on which the composite naomaterials of CNT and GNP were assembled by the optimized ration of $1: 1(\mathrm{v} / \mathrm{v})$. The in situ electropolymerization process of thionine monomer in acetonitrile solution was investigated by $\mathrm{CV}$ measurements with successive sweeps between 0 and $1.4 \mathrm{~V}$ (Fig. 1). It was found that the CVs clearly displayed a pair of anodic and cathodic peaks at 0.4 and $0.35 \mathrm{~V}$, respectively, showing an electrochemically quasireversible redox process of the PTH film with highly uniform growth. Moreover, the low difference value $(50 \mathrm{mV})$ between the anodic peak and the cathodic peak separations might indicate a fast charge transfer from PTH film to the electrode..$^{10}$

Moreover, the chemically activated CNT could achieve much higher stability once boud on the amine-terminated PTH film, due to the covalent interaction between them. The functionalized surface of the nanotubes might allow for the increased binding of enzyme molecules, in contrast to the direct adsorption of enzyme on CNT explained in some previous reports. ${ }^{25,26}$ In the meantime, GNP materials were immobilized in combination with CNT on the amine-terminated PTH film through the strong interaction of $\mathrm{Au}$ to $-\mathrm{NH}_{2}{ }^{12,14}$ The resulting PTH-CNT-GNP platform could be thus ready for anchoring 


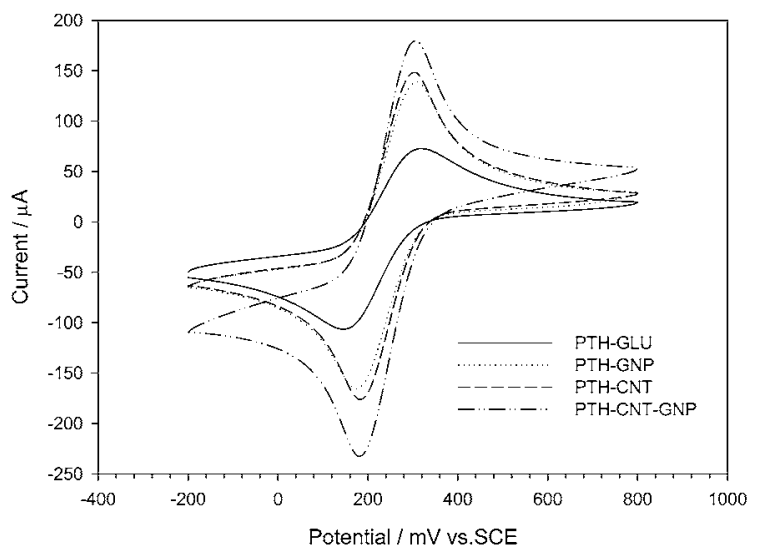

Fig. 3 Comparison of electron transfer properties among different sensing platforms of PTH-GLU, PTH-GNP, PTH-CNT, and PTHCNT-GNP, characterized by CV experiments with $10 \mathrm{mM}$ $\mathrm{K}_{3} \mathrm{Fe}(\mathrm{CN})_{6}$ containing $0.1 \mathrm{M} \mathrm{KCl}$ at a scan rate of $40 \mathrm{mV} / \mathrm{s}$.

HRP as a model enzyme. Figure 2 illustrates the preparation process of such a enzyme electrode by $\mathrm{CV}$ measurements using the redox probe of $\mathrm{K}_{3} \mathrm{Fe}(\mathrm{CN})_{6}$. As is shown in Fig. 2, the electron conduction of the PTH film to the electrode was greatly enhanced by the introduction of CNT-GNP composite but with a lower potential. Therefore, the unique electrical properties and high surface-to-volume ratio of the composite nanomaterials could make a synergic enhancement effect on the electron transfer and enzyme immobilization efficiency.

\section{Electrochemical CV characteristics between different sensing platforms}

The roles of individual components and the possible synergic effects between them in promoting the electron transfer performances of the modified electrode were investigated by comparison. Figure 3 describes a CV comparison of the redox $\mathrm{K}_{3} \mathrm{Fe}(\mathrm{CN})_{6}$ probe between the proposed PTH-CNT-GNP platform and three other PTH-based platforms using CNT or GNP alone, or using GLU. This figure shows that the developed PTH-CNT-GNP platform showed the highest peak current at basically the same potential. Thereby, such a platform should endow the modified electrode with the highest electroactive surface area according to the Randles-Sevcik equation, as described in Ref. 22. The bound CNT-GNP composite here was thought to present a unique electron transfer pathway, enabling much easier electron transfer between the redox partners of $\left[\mathrm{Fe}(\mathrm{CN})_{6}\right]^{4-}$ and $\left[\mathrm{Fe}(\mathrm{CN})_{6}\right]^{3-}$. More importantly, the amplified peak response current might reveal the presence of a synergistic effect that could lead to the increased electron-shuttling efficiency for redox reactions. We additionally noted that, with the same redox partners of $\mathrm{Fe}(\mathrm{III}) / \mathrm{Fe}(\mathrm{II})$, the cathodic oxidization and anodic reduction potentials obtained for the PTH-GLU modified electrode (Fig. 3) are somewhat lower than those for the PTH modified electrode mentioned above (Fig. 2), which might be ascribed to the covalent effects of glutaraldehyde on the electroactivity or conduction of the modified PTH molecules, as observed elsewhere. ${ }^{24}$

Figure 4 manifests the $\mathrm{CV}$ s recorded at varying scan rates for the HRP electrode with the PTH-CNT-GNP platform in the PBS (pH 7.0) containing $1.0 \mathrm{mM} \mathrm{H}_{2} \mathrm{O}_{2}$. As is shown in Fig. 4, a pair of well-defined $\mathrm{H}_{2} \mathrm{O}_{2}$ redox waves was observed with the cathodic reduction peak at $-0.7 \mathrm{~V}$ and the anodic oxidization

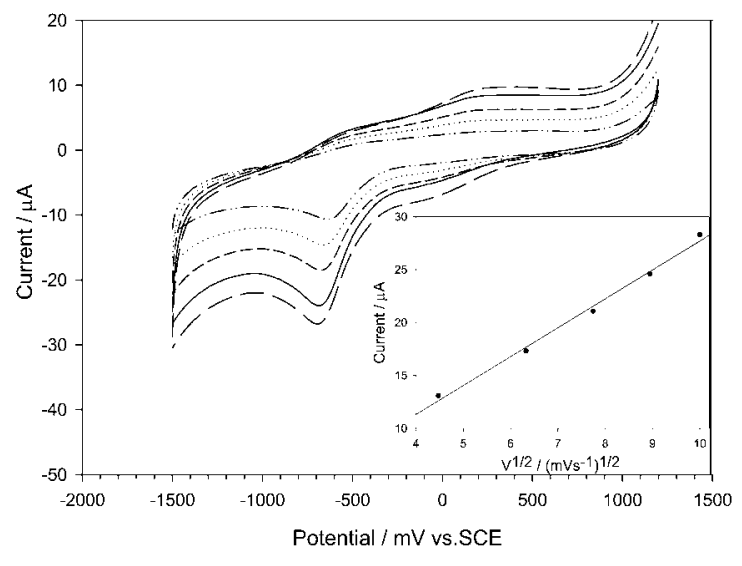

Fig. 4 CVs of enzyme electrode with the PTH-CNT-GNP platform in the PBS ( $\mathrm{pH}$ 7.0) containing $1.0 \mathrm{mM} \mathrm{H}_{2} \mathrm{O}_{2}$ at varying scan rates $(v)$ from inner to outer curves: 20, 40, 60, 80 and $100 \mathrm{mV} / \mathrm{s}$. Inset: plot of cathodic peak current $v s$. $v^{1 / 2}$.

peak at $0.2 \mathrm{~V}$. The plot of cathodic current $v s$. the square root of scan rate showed a good linear relation (inset in Fig. 4), indicating a diffusion-controlled electrode process. Similar CV results were also observed at the electrodes fabricated separately with the PTH-GLU and the PTH-GNP platforms. However, the $\mathrm{CV}$ profiles recorded for the HRP electrode with the PTH-CNT platform were surprisingly different; here poorly-defined $\mathrm{H}_{2} \mathrm{O}_{2}$ redox waves were obtained under the same measurement conditions (Fig. 5C vide infra). Such a phenomenon may be explained by the additional participation of the intrinsic direct electrocatalysis action of CNT toward hydrogen peroxide. ${ }^{27}$ As a result, the procedure is assumed to give rise to a complicated mediating process of electron transfer reactions, and a different HRP electrocatalytic response to $\mathrm{H}_{2} \mathrm{O}_{2}$. The above results might again demonstrate the unique roles of GNP and CNT with a synergic effect in enhancing the electrochemical biosensing properties of the as-prepared enzyme electrode.

Furthermore, the $\mathrm{CV}$ characteristics towards $\mathrm{H}_{2} \mathrm{O}_{2}$ for the four enzyme sensors were comparably studied in the working PBS (pH 7.0) with and without $\mathrm{H}_{2} \mathrm{O}_{2}$ (Fig. 5). As are shown in Fig. 5 , a pair of oxidation-reduction peaks was observed for all sensors in the absence of $\mathrm{H}_{2} \mathrm{O}_{2}$ except for varying profiles of $\mathrm{CV}$ curves, showing the typical electrochemical behavior of different mediating modifiers on these electrodes. There was a significant difference among these sensors in terms of the increased peak value of cathodic response to $\mathrm{H}_{2} \mathrm{O}_{2}$. The enzyme sensor with the PTH-CNT-GNP platform exhibited the highest cathodic peak current (Fig. 5D), whereas the sensor with the PTH-GLU platform presented the lowest one (Fig. 5A). To the same $\mathrm{H}_{2} \mathrm{O}_{2}$ concentration, here, the current response sensitivities for the PTH-CNT-GNP, the PTH-CNT (Fig. 5C), the PTH-GNP (Fig. 5B) and the PTH-GLU platforms are estimated to be $\sim 287$, $\sim 82, \sim 57$ and $\sim 20 \mu \mathrm{A} / \mathrm{cm}^{2}$, respectively. Accordingly, there is 3.5 - 14 fold increase in the current response sensitivities for the enzyme sensor using the composite nanomaterials.

\section{Direct amperometric responses to $\mathrm{H}_{2} \mathrm{O}_{2}$ for different enzyme} sensors

The direct amperometric responses to hydrogen peroxide were investigated for the enzyme sensors fabricated by different biosensing platforms, measured separately in a stirred PBS $(\mathrm{pH}$ 7.0) at $0.4 \mathrm{~V} v s$. SCE. Figure 6 shows the $\mathrm{H}_{2} \mathrm{O}_{2}$ calibration curves at four different enzyme electrodes. The enzyme sensor 

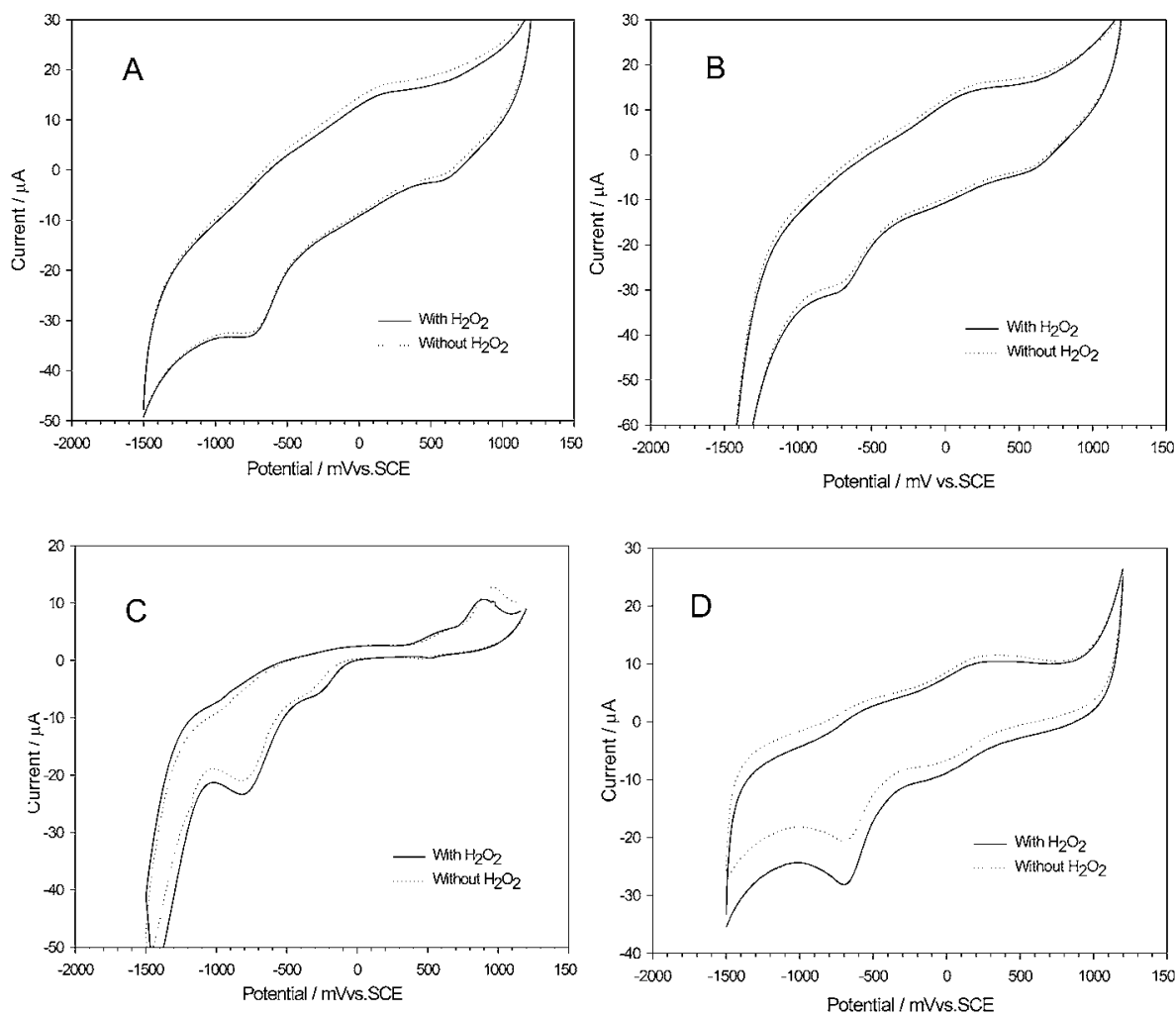

Fig. 5 Comparison of $\mathrm{CV}$ characteristics when probing $\mathrm{H}_{2} \mathrm{O}_{2}$ between enzyme electrodes with different platforms of (A) PTH-GLU, (B) PTH-GNP, (C) PTH-CNT, and (D) PTH-CNT-GNP, measured in the PBS (pH 7.0) with and without $1.0 \mathrm{mM} \mathrm{H}_{2} \mathrm{O}_{2}$ at a scan rate of $100 \mathrm{mV} / \mathrm{s}$.

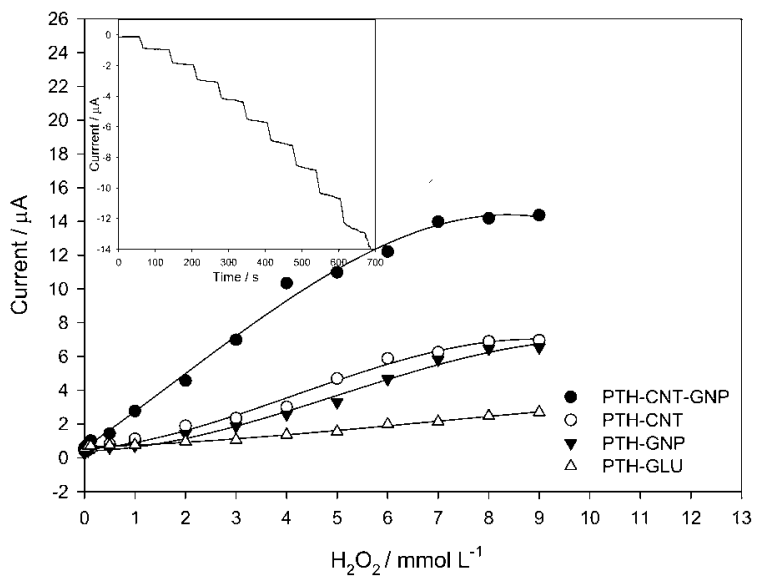

Fig. 6 Calibration plots of current responses versus $\mathrm{H}_{2} \mathrm{O}_{2}$ concentrations at enzyme sensors with different platforms using an applied potential of $-0.4 \mathrm{~V}$. Inset: the current-time recordings for the enzyme electrode with the PTH-CNT-GNP platform upon successively increasing the $\mathrm{H}_{2} \mathrm{O}_{2}$ concentration in steps of $0.5 \mathrm{mM}$.

with the PTH-CNT-GNP platform showed the best amperometric performances in terms of the linear range, the detection limit $(S / N=3)$, and the assay sensitivity. The results for four sensors with different sensing platforms are summarized in Table 1. For the proposed HRP sensor, the current responses are linearly related to $\mathrm{H}_{2} \mathrm{O}_{2}$ concentrations ranging from $5.0 \times 10^{-6}$ to $7.0 \times 10^{-3} \mathrm{M}$, with the detection limit of $3.0 \times 10^{-6} \mathrm{M}$ and the assay sensitivity of $2.095 \mathrm{Ma} / \mathrm{M}$. Moreover, a typical current-time response to increasing levels of $\mathrm{H}_{2} \mathrm{O}_{2}$ in $0.5 \mathrm{mM}$ steps was exemplified for the electrode with the PTH-CNT-GNP platform (insert in Fig. 6). Results show that the proposed sensors displayed fast and sensitive responses to the additions of $\mathrm{H}_{2} \mathrm{O}_{2}$. The response to $\mathrm{H}_{2} \mathrm{O}_{2}$ reached a steady-state current signal of $95 \%$ within $10 \mathrm{~s}$.

Moreover, repeated usages of the developed sensor did not affect its amperometric performances, and good reproducibility was achieved. For example, when $1.0 \mathrm{mM} \mathrm{H}_{2} \mathrm{O}_{2}$ was measured continuously for 5 runs, a relative standard deviation (RSD) of $5.8 \%$ was obtained for the studied $\mathrm{H}_{2} \mathrm{O}_{2}$ electrode. The excellent reproducibility might also prove the manipulation stability of the enzyme bound by the PTH-CNT-GNP platform. The storage stability of the enzyme sensor with the PTH-CNTGNP platform was further examined by repetitive measurements for the response to $1.0 \mathrm{mM} \mathrm{H}_{2} \mathrm{O}_{2}$ during one month. When not in usage, the sensor was stored in the PBS $\left(\mathrm{pH} \mathrm{7.0)}\right.$ at $4^{\circ} \mathrm{C}$. With intermittent measurements of the current response every other day, the proposed sensor was verified to allow for $85 \%$ retention of its initial response sensitivity, showing long-term stability of the studied enzyme electrode.

\section{Conclusions}

There are some attractive merits in the proposed biosensing platform design with $\mathrm{CV}$ investigations. Firstly, the direct modification of the outstanding mediating redox PTH on the electrode may facilitate a reagentless electrochemical assay, avoiding the addition of an electron transfer mediator to the solution and the formidable separation step, thus simplifying the electroanalytical procedure and shortening the assay time. Secondly, the introduction of the CNT and GNP composite 
Table 1 Comparisons of amperometric responses to $\mathrm{H}_{2} \mathrm{O}_{2}$ among the enzyme sensors with different sensing platforms

\begin{tabular}{lcll}
\hline $\begin{array}{c}\text { Sensing } \\
\text { platform }\end{array}$ & $\begin{array}{c}\text { Linear } \\
\text { range/M }\end{array}$ & $\begin{array}{c}\text { Detection } \\
\text { limit/M }\end{array}$ & $\begin{array}{c}\text { Assay } \\
\text { sensitivity/ } \\
\mathrm{mA} \mathrm{M}^{-1 c}\end{array}$ \\
\hline PTH-CNT-GNP & $5.0 \times 10^{-6}-7.0 \times 10^{-3}$ & $3.0 \times 10^{-6}$ & 2.095 \\
PTH-CNT & $5.5 \times 10^{-5}-6.0 \times 10^{-3}$ & $2.5 \times 10^{-5}$ & 0.2332 \\
PTH-GNP & $9.0 \times 10^{-5}-6.0 \times 10^{-3}$ & $5.0 \times 10^{-5}$ & 0.2558 \\
PTH-GLU & $1.3 \times 10^{-4}-5.0 \times 10^{-3}$ & $0.8 \times 10^{-4}$ & 0.0992 \\
\hline
\end{tabular}

a. The linear ranges $(\mathrm{M})$ are obtained by fitting the calibration curves for determination of $\mathrm{H}_{2} \mathrm{O}_{2}$ with different concentrations.

b. The detection limits $(\mathrm{M})$ are estimated by the rule of $S / N=3$.

c. The assay sensitivities $\left(\mathrm{mA} \mathrm{M}^{-1}\right)$ are obtained from the slopes of the fitted regression lines.

nanomaterials could achieve the electrochemical properties of the individual components with a synergistic effect, which may promote the electron transfer and increase the enzyme immobilization efficiency of the electrode. Thirdly, the developed platform could allow for HRP bound with wellretained electrocatalytic activities and fast amperometric responses. It might also offer a desirably stable matrix for the firm immobilization of enzyme, facilitating a good assay reproducibility and long-term stability of sensor. This new platform design may be extended as a new direct electrochemical biosensing design that provides operational access to a large scale of oxidase-based enzymes for wide biosensor applications.

\section{Acknowledgements}

This work was supported by the NNSF of China (Nos. 20375012 and 20435010), and the Science Commission of Hunan Province.

\section{References}

1. K. Habermüller, M. Mosbach, and W. Schuhmann, Fresenius J. Anal. Chem., 2000, 366, 560.

2. Y. Degani and A. Heller, J. Phys. Chem., 1987, 91, 1285.

3. J. Haccoun, B. Piro, L. D. Tran, L. A. Dang, and M. C. Pham, Biosens. Bioelectron., 2004, 19, 1325.

4. J. B. Jia, B. Q. Wang, A. G. Wu, G. J. Cheng, Z. Li, and S.
J. Dong, Anal. Chem., 2002, 74, 2217.

5. L. Gorton, A. Lindgren, T. Larsson, F. D. Munteanu, T. Ruzgas, and I. Gazaryan, Anal. Chim. Acta, 1999, 400, 91.

6. A. Heller, J. Phys. Chem., 1992, 96, 3579.

7. T. Tatsuma, M. Gondaira, and T. Watanabe, Anal. Chem., 1992, 64, 1183.

8. Y. Degani and A. Heller, J. Am. Chem. Soc., 1989, 111, 2357.

9. Q. Deng and S. J. Dong, J. Electroanal. Chem., 1994, 377, 191.

10. C. M. Ruan, F. Yang, C. H. Lei, and J. Q. Deng, Anal. Chem., 1998, 70, 1721.

11. C. R. Martin and D. T. Mitchell, Anal. Chem., 1998, 70, 322A.

12. K. R. Brown, A. P. Fox, and M. J. Natan, J. Am. Chem. Soc., 1996, 118, 1154

13. K. C. Grabar, R. G. Freeman, M. B. Hommer, and M. J. Natan, Anal. Chem., 1995, 67, 735.

14. H. Wang, C. C. Wang, C. X. Lei, Z. Y. Wu, G. L. Shen, and R. Q. Yu, Anal. Bioanal. Chem., 2003, 377, 632.

15. H. Li, J. X. Wen, Q. Cai, X. L. Wang, J. M. Xu, and L. T. Jin, Analyst, 2001, 126, 1747.

16. A. L. Crumbliss, S. C. Perine, J. Stonehuerner, K. R. Tubergen, J. G. Zhao, and R. W. Henkens, Biotechnol. Bioeng., 1992, 40, 483.

17. J. Wang and M. Musameh, Anal. Chem., 2003, 75, 2075.

18. M. G. Zhang and W. Gorski, J. Am. Chem. Soc., 2005, 127, 2058.

19. A. Star, J. S. Stoddart, D. Streuerman, M. Diehl, A. Boukai, E. W. Wong, X. Yang, S. W. Chung, H. Choi, and J. R. Heath, Angew. Chem., Int. Ed., 2001, 40, 1721.

20. P. P. Joshi, S. A. Merchant, Y. D. Wang, and D. W. Schmidtke, Anal. Chem., 2005, 77, 3183.

21. Q. W. Li, J. Zhang, H. Yan, M. S. He, and Z. F. Liu, Carbon, 2004, 42, 287.

22. S. Hrapovic, Y. L. Liu, K. B. Male, and J. H. T. Luong, Anal. Chem., 2004, 76, 1083.

23. M. H. Yang, Y. Yang, H. F. Yang, G. L. Shen, and R. Q. Yu, Biomaterials, 2006, 27, 246.

24. R. Yang, C. M. Ruan, W. L. Dai, J. Q. Deng, and J. L. Kong, Electrochim. Acta, 1999, 44, 1585.

25. B. R. Azamian, J. J. Davis, K. S. Coleman, C. B. Bagshaw, and M. L. H. Green, J. Am. Chem. Soc., 2002, 124, 12664.

26. A. Guiseppi-Elie, C. H. Lei, and R. H. Baughman, Nanotechnology, 2002, 13, 559.

27. J. Wang, M. Musameh, and Y. H. Lin, J. Am. Chem. Soc., 2003, 125, 2408 . 